\title{
PENGARUH BRAND IMAGE, BRAND TRUST DAN PERCEIVED QUALITY TERHADAP BRAND LOYALTY ADIDAS PADA CHELSEA INDONESIA SUPPORTER CLUB (CISC) DI DEPOK
}

\author{
Farid Al Rizky \\ M. Agung S. Utomo \\ Email: Farid_Alrizky88@yahoo.co.id, agsatryo@gmail.com \\ Program Studi Manajemen Fakultas Ekonomi \\ Universitas Nasional
}

\begin{abstract}
ABSTRAK
Penelitian ini bertujuan untuk menguji dan menganalisis pengaruh brand image, brand trust dan perceived quality terhadap brand loyalty Adidas pada Chelsea Indonesia Supporter Club di Depok. Data dikumpulkan dengan survey melalui penyebaran kuesioner. Data dianalisis dengan menggunakan regresi linear berganda. Dengan menggunakan rumus Slovin, jumlah sampel yang digunakan dalam penelitian ini adalah 100 responden. Hasil penelitian menunjukkan bahwa brand image, brand trust dan perceived quality secara parsial berpengaruh positif dan signifikan terhadap brand loyalty Adidas pada Chelsea Indonesia Supporter Club di Depok.
\end{abstract}

Kata kunci: Brand image, brand trust, perceived quality, brand loyalty

\section{ABSTRACT}

This study aims to test and analyze the effect of brand image, brand trust and perceived quality on Adidas brand loyalty in Chelsea Indonesia Supporter Club at Depok. Data collected by survey through questionnaires distribution. Data analyzed by multiple linear regression. By used Slovin formula, the amount of samples used in this study was 100 respondents. Results of the study showed that brand image, brand trust and perceived quality partially has positive and significant effect on Adidas brand loyalty in Indonesia Chelsea Supporter Club at Depok.

Keywords: Brand image, brand trust, perceived quality, brand loyalty

\section{PENDAHULUAN}

Sepakbola merupakan salah satu cabang olahraga yang paling populer dan digemari di seluruh dunia. Dilansir oleh sports venues, rata-rata penonton yang hadir di pertandingan sepak bola di Eropa mencapai 80,410 per pertandingan pada tahun 2015. Sebagai olahraga dengan peminat terbesar di seluruh dunia, sepakbola merupakan industri bisnis yang sangat menggiurkan. Penghasilan klub-klub sepakbola di berbagai liga di dunia bukan hanya berasal dari penjualan tiket pertandingan dan pemain, tetapi juga berasal dari penjualan merchandise, hak siar televisi dan sponsor. Fanatisme di dalam diri penggemar sepak bola membuat mereka rela mengeluarkan uang untuk membeli berbagai macam merchandise yang berkaitan dengan klub sepak bola favoritnya. 
Berbagai perusahaan datang dan menawarkan diri kepada klub untuk menjadi sponsor agar produknya makin dikenal, sehingga penjualan dan keuntungannya meningkat. Merchandise merupakan salah satu langkah produsen untuk memanfaatkan peluang bisnis dengan adanya supporter dan komunitas bola. Merchandise yang dijual di counter resmi merupakan barang original yang dijual disetiap counter yang tersebar di dunia. Banyak bermacam-macam varian merchandise tersedia di sana seperti jersey, sepatu, celana, sarung tangan kiper, bola dan masih banyak lainnya. Oleh karena itu, merchandise merupakan hal yang paling dibutuhkan supporter untuk mendukung klub kesayangan. Hal tersebut menyebabkan supporter bola mengenal brand yang menjadi apparel klub dan menimbulkan loyalitas terhadap merek.

Dalam hal apparel, Chelsea bekerjasama dengan perusahaan Adidas, salah satu perusahaan yang bergerak di bidang tekstil yang secara khusus lebih memproduksi produkproduk olahraga. Berdasarkan survei yang dilakukan oleh majalah marketing dan SWA, majalah yang berfokus pada dunia pemasaran di Indonesia, Adidas berhasil meraih predikat Top Brand pada tahun 2013-2015.

Tabel 1. Top Brand Index Produk Olahraga Tahun 2013-2015

\begin{tabular}{|r|l|r|r|r|}
\hline \multirow{2}{*}{ No } & \multirow{2}{*}{ Merek } & \multicolumn{3}{|c|}{ Top Brand Index (\%) } \\
\cline { 3 - 5 } & & $\mathbf{2 0 1 3}$ & $\mathbf{2 0 1 4}$ & $\mathbf{2 0 1 5}$ \\
\hline 1 & Adidas & 57,9 & 58,4 & 56,8 \\
\hline 2 & Nike & 22,1 & 24,8 & 27,3 \\
\hline 3 & Puma & 5,1 & 4,9 & 4,6 \\
\hline 4 & Under Armour & 2,3 & 2,8 & 3,9 \\
\hline
\end{tabular}

(Sumber: Top Brand Award, 2016)

Adidas mendapatkan predikat pertama Top Brand tahun 2013-2015 pada kategori produk-produk olahraga. Akan tetapi, Adidas mengalami penurunan persentase top brand index dari 58,4\% di tahun 2014 ke 56,8\% di tahun 2015 .

Adidas mendapatkan predikat Top Brand Award di Indonesia, tetapi pendapatan global Adidas justru lebih kecil daripada pendapatan global Nike selaku pesaingnya. 


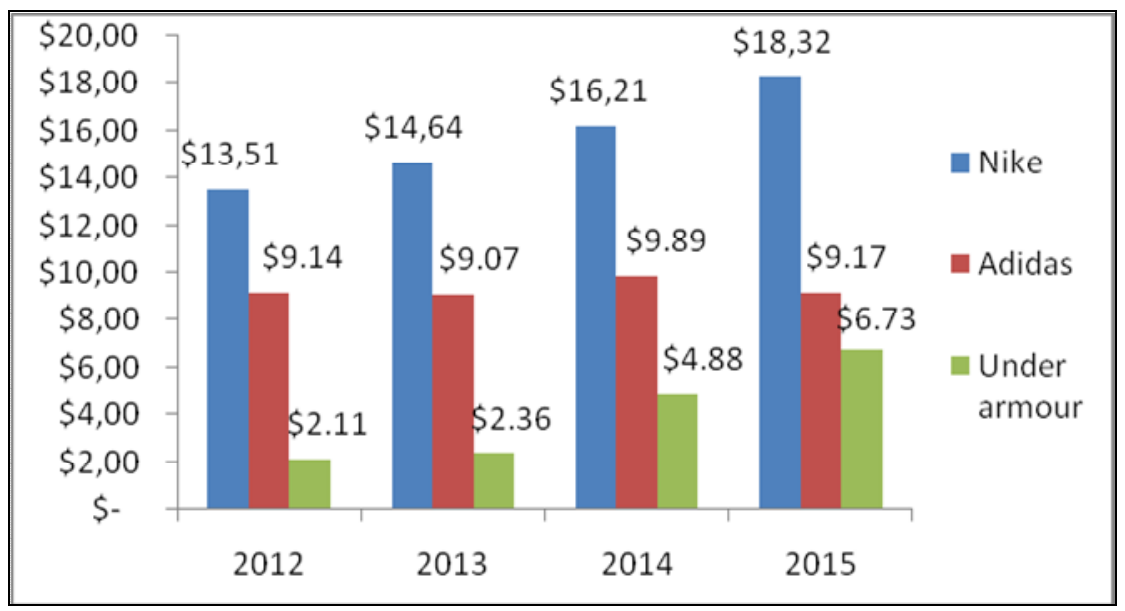

(Sumber: Statista, 2016)

Gambar 1. Pendapatan dari Segmen Sepatu Olahraga

Nike, Adidas dan Under Armour Tahun 2012-2015

(Dalam Miliar Dolar AS)

Berdasarkan gambar di atas, pendapatan global Adidas tertinggal dari Nike selaku pesaingnya. Bahkan, Adidas mengalami penurunan pendapatan dari $\$ 9,89$ miliar dolar di tahun 2014 menjadi \$9,17 miliar dolar di tahun 2015. Sementara itu, pendapatan Nike dan Under Armour justru mengalami peningkatan di tahun 2015. Hal tersebut dapat mengindikasikan bahwa beberapa konsumen Adidas mulai berpindah ke merek lain. Perpindahan konsumen ke produk pesaing menunjukkan kurangnya tingkat loyalitas konsumen terhadap Adidas.

Loyalitas merek merupakan suatu kondisi dimana konsumen memiliki komitmen terhadap merek dan kecenderungan untuk meneruskan pembeliannya di masa yang akan datang. Munculnya banyak perusahaan di industri yang sama mengakibatkan ketatnya persaingan di industri tersebut. Dalam rangka mengatasi penetrasi yang dilakukan oleh kompetitor, perusahaan perlu membentuk citra merek yang kuat. Tanpa citra merek (brand Image) yang kuat dan positif, sangatlah sulit bagi perusahaan untuk menarik pelanggan baru dan mempertahankan pelanggan yang sudah ada (Ismani dan Platomi, 2008: 18).

Kepercayaan merek (brand trust) akan menentukan kesetiaan konsumen terhadap suatu merek. Hal ini sejalan dengan hasil penelitian yang dilakukan oleh Bastian (2014) yang menunjukkan bahwa kepercayaan merek berpengaruh positif dan signifikan terhadap loyalitas merek. Hal tersebut menunjukkan bahwa semakin tinggi tingkat kepercayaan (trust) pelanggan terhadap suatu merek, maka semakin tinggi tingkat loyalitas pelanggan terhadap merek tersebut. 
Persepsi kualitas suatu produk oleh konsumen juga akan menentukan loyalitas konsumen tersebut terhadap suatu merek. Hasil penelitian yang dilakukan oleh Kurniati, dkk. (2013) dan Waskito (2008) menunjukkan bahwa persepsi kualitas memiliki pengaruh yang positif dan signifikan terhadap loyalitas merek. Hal tersebut menunjukkan bahwa semakin tinggi tingkat perceived quality pelanggan terhadap suatu merek, maka semakin tinggi tingkat loyalitas pelanggan terhadap merek tersebut.

Berdasarkan latar belakang di atas, perlu dilakukan penelitian untuk menguji dan menganalisis pengaruh brand image, brand trust, dan perceived quality terhadap brand loyalty Adidas pada Chelsea Indonesia Supporter Club.

\section{TINJAUAN PUSTAKA}

\section{Loyalitas Merek (Brand Loyalty)}

Menurut Bendapudi dan Berry (1997) dalam Tjiptono (2005), loyalitas pelanggan (customer loyalty) adalah respon yang terkait erat dengan ikrar atau janji untuk memegang teguh komitmen yang mendasari keberlanjutan relasi, dan biasanya tercermin dalam pembelian ulang yang konsisten. Menurut Rangkuti (2008), loyalitas merek adalah suatu ukuran kesetiaan konsumen terhadap suatu merek. Griffin (2003) berpendapat bahwa pelanggan yang loyal adalah pelanggan yang sangat puas dengan produk atau jasa tertentu sehingga mempunyai antusiasme untuk memperkenalkannya kepada siapapun yang dikenal.

\section{Citra Merek (Brand Image)}

Menurut Shimp (2003) dalam Radji dan Lesmana (2009:18), citra merek adalah asosiasi yang muncul dibenak konsumen ketika mengingat sebuah merek tertentu. Menurut Kotler dan Keller (2009), citra merek adalah sejumlah keyakinan tentang merek.

\section{Kepercayaan Merek (Brand Trust)}

Menurut Ballester (2004) dalam Ferrinnadewi (2008), kepercayaan merek adalah kemampuan merek untuk dipercaya (brand reliability) yang bersumber dari keyakinan konsumen bahwa produk tersebut mampu memenuhi nilai yang dijanjikan dan. Kepercayaan pelanggan pada merek (brand trust) dapat didefinisikan sebagai keinginan pelanggan untuk bersandar pada sebuah merek dengan resiko-resiko yang dihadapi karena ekspektasi terhadap merek itu akan menyebabkan hasil yang positif (Lau dan Lee, 1999: 344). 


\section{Persepsi Kualitas (Perceived quality)}

Menurut Tjiptono (2005:40), perceived quality adalah penilaian pelanggan terhadap keunggulan atau superioritas produk secara keseluruhan. Durianto dan Budiman (2004:96) menyatakan bahwa persepsi kualitas dapat didefinisikan sebagai persepsi pelanggan terhadap keseluruhan kualitas atau keunggulan produk. Menurut Simamora (2003), persepsi kualitas (perceived quality) adalah persepsi pelanggan terhadap kualitas atau keunggulan suatu produk atau jasa layanan ditinjau dari fungsinya secara relatif dengan produk-produk lain.

\section{Keterkaitan Antarvariabel penelitian}

\section{Keterkaitan Antara Brand Image dan Brand Loyalty}

Menurut Hogan (2005), loyalitas konsumen dipengaruhi langsung oleh pelayanan pelanggan dan citra merek. Hasil penelitian yang dilakukan oleh Bastian (2014) juga menunjukkan bahwa citra merek berpengaruh positif dan signifikan terhadap loyalitas merek. Hal tersebut menunjukkan bahwa semakin tinggi tingkat citra suatu merek, maka semakin tinggi tingkat loyalitas pelanggan terhadap merek tersebut.

$\mathrm{H}_{1}$ : Brand image berpengaruh positif dan signifikan terhadap brand loyalty Adidas pada Chelsea Indonesia Supporter Club di Depok.

\section{Hubungan antara variabel Brand Trust dengan Brand Loyalty}

Hasil penelitian yang dilakukan oleh Bastian (2014) menunjukkan bahwa kepercayaan merek berpengaruh positif dan signifikan terhadap loyalitas merek. Hal tersebut menunjukkan bahwa semakin tinggi tingkat kepercayaan (trust) pelanggan terhadap suatu merek, maka semakin tinggi tingkat loyalitas pelanggan terhadap merek tersebut.

$\mathrm{H}_{2}$ : Brand trust berpengaruh positif dan signifikan terhadap brand loyalty Adidas pada Chelsea Indonesia Supporter Club di Depok.

\section{Hubungan Perceived Quality dengan Brand Loyalty}

Menurut Aaker (2007), persepsi kualitas (perceived quality) adalah persepsi pelanggan terhadap keseluruhan kualitas atau keungulan suatu produk atau jasa layanan yang terkait dengan maksud yang diharapkan. Hasil penelitian yang dilakukan oleh Kurniati, dkk. (2013) dan Waskito (2008) menunjukkan bahwa persepsi kualitas memiliki pengaruh yang positif dan signifikan terhadap loyalitas merek. Hal tersebut menunjukkan bahwa semakin 
tinggi tingkat perceived quality pelanggan terhadap suatu merek, maka semakin tinggi tingkat loyalitas pelanggan terhadap merek tersebut.

$\mathrm{H}_{3}$ : Perceived quality berpengaruh positif dan signifikan terhadap brand loyalty Adidas pada Chelsea Indonesia Supporter Club di Depok.

\section{Kerangka Analisis}

Kerangka analisis yang digunakan dalam penelitian ini, yaitu sebagai berikut.

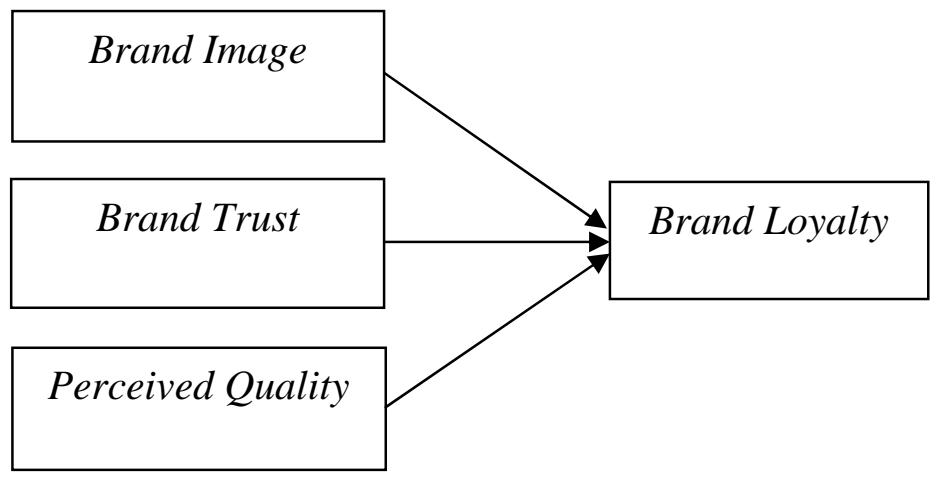

\section{Gambar 2. Kerangka Analisis}

\section{METODE PENELITIAN}

\section{Sumber dan Jenis Data}

Penelitian ini menggunakan data primer dan cross section yang bersumber dari kuesioner yang diisi oleh anggota Chelsea Indonesia Supporter Club di Depok (CISC) yang menjadi responden.

\section{Populasi dan Sampel}

Populasi dalam penelitian ini adalah anggota Chelsea Indonesia supporter Club (CISC) di Depok yang berjumlah 152 orang. Jumlah sampel ditentukan menggunakan rumus Slovin berikut.

$$
\mathrm{n}=\frac{\mathrm{N}}{1+\mathrm{Ne}^{2}}
$$

Keterangan:

$$
\begin{array}{ll}
\mathrm{n}= & \text { Ukuran sampel } \\
\mathrm{N}= & \text { Ukuran populasi } \\
\mathrm{e}= & \text { Batas toleransi kesalahan }
\end{array}
$$


Berdasarkan rumus Slovin, jumlah sampel yang digunakan dalam penelitian adalah 110 responden.

\section{Definisi Operasional Variabel}

Berikut ini merupakan definisi operasional dari variabel yang digunakan dalam penelitian ini.

Tabel 2. Definisi Operasional Variabel

\begin{tabular}{|c|c|c|}
\hline Variabel & Definisi Operasional & Indikator \\
\hline $\begin{array}{l}\text { Brand } \\
\text { loyalty }\end{array}$ & $\begin{array}{l}\text { Tingkat kesetiaan konsumen terhadap } \\
\text { suatu merek. }\end{array}$ & $\begin{array}{l}\text { 1. Rekomendasi pembeli } \\
\text { 2. Ingatan konsumen terhadap } \\
\text { merek } \\
\text { 3. Kepuasan terhadap merek }\end{array}$ \\
\hline $\begin{array}{l}\text { Brand } \\
\text { image }\end{array}$ & $\begin{array}{l}\text { Gambaran mengenai suatu merek di } \\
\text { dalam benak konsumen. }\end{array}$ & $\begin{array}{l}\text { 1. Kualitas yang baik } \\
\text { 2. Karakteristik yang lebih baik } \\
\text { daripada pesaing } \\
\text { 3. Salah satu merek terbaik di } \\
\text { industrinya }\end{array}$ \\
\hline Brand trust & $\begin{array}{l}\text { Tingkat kesediaan konsumen untuk } \\
\text { mempercayai suatu merek. }\end{array}$ & $\begin{array}{l}\text { 1. Kepercayaan pelanggan pada } \\
\text { reputasi perusahaan } \\
\text { 2. Keamanan } \\
\text { 3. Keyakinan pelanggan akan } \\
\text { manfaat dan kualitas produk } \\
\text { yang ditawarkan. }\end{array}$ \\
\hline $\begin{array}{l}\text { Perceived } \\
\text { quality }\end{array}$ & $\begin{array}{l}\text { Penilaian pelanggan terhadap kualitas } \\
\text { produk. }\end{array}$ & $\begin{array}{l}\text { 1. Kesesuaian dengan spesifikasi } \\
\text { 2. Keunggulan } \\
\text { 3. Kecocokan untuk digunakan }\end{array}$ \\
\hline
\end{tabular}

\section{Metode Analisis}

Metode analisis yang digunakan dalam penelitian ini adalah regresi linear berganda yang digunakan untuk menganalisis pengaruh brand image, brand trust dan perceived quality terhadap brand loyalty Adidas pada Chelsea Indonesia Supporter Club di Depok.

\section{HASIL PENELITIAN DAN PEMBAHASAN}

\section{Uji Instrumen}

\section{Uji Validitas}

Berdasarkan hasil uji validitas, semua butir pernyataan dari kuesioner memiliki $\mathrm{r}$ hitung > r tabel, sehingga dinyatakan valid. 


\section{Uji Reliabilitas}

Berdasarkan hasil uji reliabilitas, nilai Cronbach Alpha semua variabel berada di atas 0,6 , sehingga dinyatakan reliabel.

\section{Uji Asumsi klasik}

\section{Uji Multikolinearitas}

\section{Tabel 3. Hasil Uji Multikolinearitas}

\begin{tabular}{|l|r|r|}
\hline \multirow{2}{*}{ Variabel } & \multicolumn{2}{|c|}{ Collinearity Statistics } \\
\cline { 2 - 3 } & Tolerance & \multicolumn{1}{c|}{ VIF } \\
\hline Brand image & 0.329 & 3.042 \\
\hline Brand trust & 0.626 & 1.598 \\
\hline Perceived quality & 0.378 & 2.644 \\
\hline
\end{tabular}

(Sumber: Data diolah, 2016)

Berdasarkan tabel di atas, dapat diketahui bahwa setiap variabel mempunyai nilai tolerance $>0,1$ dan nilai VIF $<10$, sehingga tidak terdapat multikolinearitas antar variabel bebas dalam model regresi ini.

\section{Uji Heteroskedastisitas}

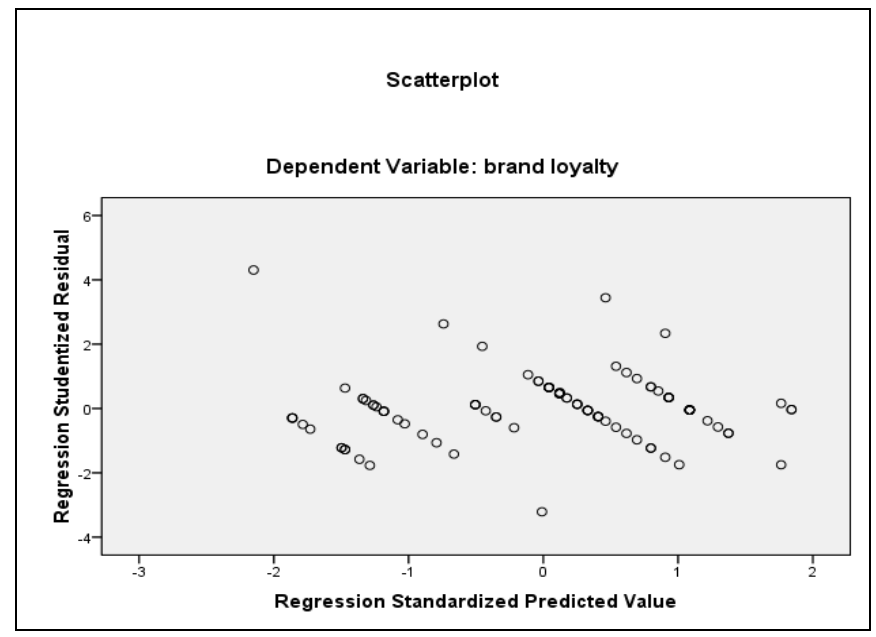

(Sumber: Data diolah, 2016)

\section{Gambar 3. Scatterplot Hasil Uji Heteroskedastisitas}

Berdasarkan gambar di atas, dapat dilihat bahwa titik-titik menyebar dan tidak membentuk suatu pola yang jelas, sehingga tidak terjadi heteroskedastisitas dalam model regresi ini. 


\section{Analisis Regresi Linear Berganda}

Tabel 4. Hasil Analisis Regresi Linear Berganda

\begin{tabular}{|l|c|r|r|r|r|}
\hline \multirow{2}{*}{ Variabel } & \multicolumn{2}{|c|}{$\begin{array}{c}\text { Unstandardized } \\
\text { Coefficients }\end{array}$} & $\begin{array}{c}\text { Standardized } \\
\text { Coefficients }\end{array}$ & \multirow{2}{*}{ t } & \multirow{2}{*}{ Sig. } \\
\cline { 2 - 4 } & B & Std. Error & \multicolumn{1}{c|}{ Beta } & & \\
\hline (Constant) & 0.123 & 0.543 & & 0.228 & 0.821 \\
Brand image & 0.514 & 0.068 & 0.504 & 7.607 & 0.000 \\
Brand trust & 0.102 & 0.048 & 0.102 & 2.123 & 0.036 \\
Perceived quality & 0.378 & 0.057 & 0.409 & 6.620 & 0.000 \\
\hline
\end{tabular}

(Sumber: Data diolah, 2016)

Berdasarkan tabel di atas, persamaan regresi linear berganda dalam penelitian ini dirumuskan sebagai berikut.

$$
Y=0,123+0,514 X 1+0,102 X 2+0,378 X 3
$$

Keterangan:

$$
\begin{array}{ll}
\mathrm{Y} & =\text { Brand loyalty } \\
\mathrm{X} 1 & =\text { Brand image } \\
\mathrm{X} 2 & =\text { Brand trust } \\
\mathrm{X} 3 & =\text { Perceived quality }
\end{array}
$$

\section{Uji Kelayakan Model (Uji F)}

Tabel 5. Hasil Uji F

\begin{tabular}{|l|r|r|r|r|r|}
\hline \multicolumn{1}{|c|}{ Model } & \multicolumn{1}{|c|}{$\begin{array}{c}\text { Sum of } \\
\text { Squares }\end{array}$} & df & $\begin{array}{c}\text { Mean } \\
\text { Square }\end{array}$ & F & Sig. \\
\hline Regression & 170.583 & 3 & 56.861 & 199.101 & 0.000 \\
Residual & 27.417 & 96 & 0.286 & & \\
Total & 198.000 & 99 & & & \\
\hline
\end{tabular}

(Sumber: Data diolah, 2016)

Berdasarkan tabel di atas, diperoleh nilai signifikan sebesar $0,000<0,05$, sehingga brand image, brand trust dan perceived quality secara bersama-sama berpengaruh signifikan terhadap kinerja karyawan. Artinya, model yang dikembangkan dalam penelitian ini layak dan variabel yang digunakan dalam model mampu menjelaskan model yang dianalisis. 


\section{Pengujian Hipotesis (Uji T)}

Tabel 6. Hasil Uji T

\begin{tabular}{|l|c|c|c|}
\hline \multicolumn{1}{|c|}{ Variabel } & $\mathbf{t}$ & Sig. & Keterangan \\
\hline Brand image & 7.607 & 0.000 & Positif dan signifikan \\
Brand trust & 2.123 & 0.036 & Positif dan signifikan \\
Perceived quality & 6.620 & 0.000 & Positif dan signifikan \\
\hline
\end{tabular}

(Sumber: Data diolah, 2016)

Berdasarkan tabel di atas, dapat diketahui bahwa brand image, brand trust dan perceived quality secara parsial berpengaruh positif dan signifikan terhadap brand loyalty.

\section{Pembahasan}

\section{Pengaruh Brand Image terhadap Brand Loyalty}

Berdasarkan hasil penelitian, brand image berpengaruh positif dan signifikan terhadap brand loyalty Adidas pada Chelsea Indonesia Supporter Club di Depok. Hal tersebut sejalan dengan hasil penelitian yang dilakukan oleh Bastian (2014). Hal ini dikarenakan gambaran dari suatu merek di benak konsumen dapat menentukan tingkat kesetiaan konsumen terhadap merek tersebut. Semakin baik citra suatu merek, maka semakin tinggi tingkat loyalitas pelanggan terhadap merek tersebut.

\section{Pengaruh Brand Trust terhadap Brand Loyalty}

Berdasarkan hasil penelitian, brand trust berpengaruh positif dan signifikan terhadap brand loyalty Adidas pada Chelsea Indonesia Supporter Club di Depok. Hal tersebut sejalan dengan hasil penelitian yang dilakukan oleh Bastian (2014). Hal ini dikarenakan tingkat kepercayaan konsumen terhadap suatu merek dapat menentukan tingkat kesetiaan konsumen terhadap merek tersebut. Semakin baik tingkat kepercayaan atas suatu merek, maka semakin tinggi tingkat loyalitas pelanggan terhadap merek tersebut.

\section{Pengaruh Perceived Quality terhadap Brand Loyalty}

Berdasarkan hasil penelitian, perceived quality berpengaruh positif dan signifikan terhadap brand loyalty Adidas pada Chelsea Indonesia Supporter Club di Depok. Hal tersebut sejalan dengan hasil penelitian yang dilakukan oleh Kurniati, dkk. (2013) dan Waskito (2008). Hal ini dikarenakan persepsi konsumen terhadap kualitas dari suatu merek 
dapat menentukan tingkat kesetiaan konsumen terhadap merek tersebut. Semakin baik kualitas yang dipersepsikan oleh konsumen atas suatu merek, maka semakin tinggi tingkat loyalitas pelanggan terhadap merek tersebut.

\section{KESIMPULAN DAN SARAN}

\section{Kesimpulan}

Berdasarkan hasil penelitian ini, dapat disimpulkan bahwa brand image, brand trust dan perceived quality secara parsial berpengaruh positif dan signifikan terhadap brand loyalty Adidas pada Chelsea Indonesia Supporter Club di Depok.

\section{Saran}

Berdasarkan hasil penelitian ini, Adidas perlu mempertahankan dan meningkatkan brand image, brand trust dan perceived quality-nya agar dapat meningkatkan brand loyalty pelanggannya. Peneliti selanjutnya diharapkan dapat menambahkan variabel lain seperti brand awareness dan other proprietary brand assets untuk menjelaskan brand loyalty Adidas.

\section{DAFTAR PUSTAKA}

Aaker, D. 2007. Manajemen Ekuitas Merek. Spektrum Mitra Utama. Jakarta.

Ballester, E.D. 2004. Applicability of Brand Trust Scale Accross Product Category. European Journal of Marketing. 38 (5): 573-592.

Bastian, D.A. 2014. Analisa Pengaruh Citra Merek (Brand Image) dan Kepercayaan Merek (Brand Trust) terhadap Loyalitas Merek (Brand Loyalty) ADES PT Ades Alfindo Putra Setia. Jurnal Manajemen Pemasaran Petra. 2(1): 1-9.

Durianto, D. S. dan L. J. Budiman. 2004. Brand Equity Ten: Strategi Memimpin Pasar. Edisi Pertama. PT Gramedia Pustaka Utama. Jakarta.

Ferrinadewi, E. 2008. Merek dan Psikologi Konsumen. Edisi Pertama. Graha Ilmu. Yogyakarta.

Griffin, J. 2003. Customer Loyalty. Edisi Revisi. Erlangga. Jakarta.

Hogan, S. 2005. Employees and Image: Bringing Brand Image to Life. The 2nd Annual Strategic Public Relations Conference. Lippincot Mercer. Chicago.

Ismani dan Platomi. 2008. Pengaruh Citra Merek. FISIP UI. Depok. 
Kotler dan Keller. 2009. Marketing Management. 13th Edition. Prentice Hall. New Jersey. Terjemahan B. Sabran. 2009. Manajemen Pemasaran. Edisi 13. Jilid 1. Erlangga. Jakarta.

Kurniati, A.D., N. Farida dan S. Nurseto. 2013. Pengaruh Kesadaran Merek dan Persepsi Kualitas terhadap Loyalitas Merek melalui Kepercayaan Merek sebagai Variabel Intervening pada Ponsel Nokia: Studi pada Mahasiswa FISIP Universitas Diponegoro. Jurnal Ilmu Administrasi Bisnis. 2(1): 1-9.

Lau, G. dan S. Lee. 2000. Costumer Trust in a Brand and Link to Brand Loyalty. Journal of Market Focused Management. 4: 341-370.

Radji dan D. Lesmana. 2009. Strategi Promosi yang Kreatif dan Analisis Kasus Intergrated Marketing Communication. Jurnal Bisnis dan Manajemen. 10 (1): 17-34.

Rangkuti, F. 2008. The Power Of Brands: Teknik Mengelola Brand Equity dan Strategi Pengembangan Merek dan Analisis Kasus dengan SPSS. Edisi Pertama. PT Gramedia Pustaka Utama. Jakarta.

Shimp, T. A. 2003. Periklanan Promosi Aspek Tambahan Komunikasi Pemsaran Terpadu. Edisi kelima. Erlangga. Jakarta.

Simamora. 2003. Membongkar Kotak Hitam Konsumen. Gramedia Pustaka Utama. Jakarta.

Tjiptono, F. et al. 2005. Pemasaran Strategik. CV Andi. Yogyakarta.

Waskito, A. 2008. Pengaruh Brand Awareness, Brand Association dan Perceived Quality terhadap Loyalitas Pelanggan Motor Merek Honda: Studi Kasus di Kota Semarang. Dinamika Ekonomi. 